\title{
Glucose Administration Downregulates Lipoprotein Lipase Activity in vivo: a Study Using Repeated Intravenous Fat Tolerance Test
}

\author{
E. JINDŘICHOVÁ ${ }^{1,2}$, S. KRATOCHVÍLOVÁ ${ }^{1}$, J. KOVÁŘ $\check{R}^{1,2}$ \\ ${ }^{1}$ Institute for Clinical and Experimental Medicine and ${ }^{2}$ Centre for Cardiovascular Research, \\ Prague, Czech Republic
}

Received January 26, 2006

Accepted March 22, 2006

On-line available March 23, 2006

\begin{abstract}
Summary
Lipoprotein lipase (LPL) is a key factor determining the clearance of triglycerides from the circulation. The enzyme activity is tissue-specifically regulated by insulin, but it is not clear yet how insulin regulates the total LPL activity in the circulation. To answer such question, we measured LPL activity using the intravenous fat tolerance test (IVFTT) that was carried out $1 \mathrm{~h}$ before as well as $2 \mathrm{~h}$ and $4 \mathrm{~h}$ after oral administration of glucose $(75 \mathrm{~g})$ in eleven healthy male volunteers. In control experiments, no glucose was given to the subjects. Glucose administration resulted in an expected increase in plasma glucose and insulin and in a suppression of non-esterified fatty acid concentration. The LPL activity assessed in IVFTT as a $\mathrm{k}_{2}$ rate constant did not change in control experiments and decreased to $78 \%$ and $73 \%$ of baseline values $2 \mathrm{~h}$ and $4 \mathrm{~h}$ after glucose administration, respectively $(\mathrm{p}=0.01)$. Similarly, LPL activity measured in the plasma after intravenous injection of heparin at the end of the experiments was $16 \%$ lower $(p<0.05)$ after glucose administration. In conclusion, LPL activity is already downregulated in vivo $2 \mathrm{~h}$ after glucose administration. The results of our study indicate that repeated IVFTT is a promising approach for studying acute changes in LPL activity.
\end{abstract}

\section{Key words}

Lipoprotein lipase $\bullet$ Glucose $\bullet$ Insulin $\bullet$ Triglyceride $\bullet$ Intravenous fat tolerance test

\section{Introduction}

Lipoprotein lipase (LPL) plays a key role in the regulation of plasma triglyceride (TG) concentration (Olivecrona and Olivecrona 1999, Mead et al. 2002). It hydrolyses triglycerides of triglyceride-rich lipoproteins (TRL) - very low density lipoproteins (VLDL) and chylomicrons. Therefore, its activity determines the rate of triglyceride clearance from the circulation. The enzyme activity is regulated in a tissue-specific manner so that fatty acids are released and then taken up in the tissues that utilize them at a given time (Eckel 1989, Zechner 1997). Insulin has been shown to upregulate LPL activity in the adipose tissue and downregulate it in the muscle (Lithell et al. 1978, Sadur and Eckel 1982, YkiJärvinen et al. 1984, Farese et al. 1991) so when the supply of glucose for oxidation is sufficient, fatty acids are stored in adipose tissue. However, it is not entirely clear yet what is the effect of insulin on the change of total LPL activity in the circulation (that should represent 


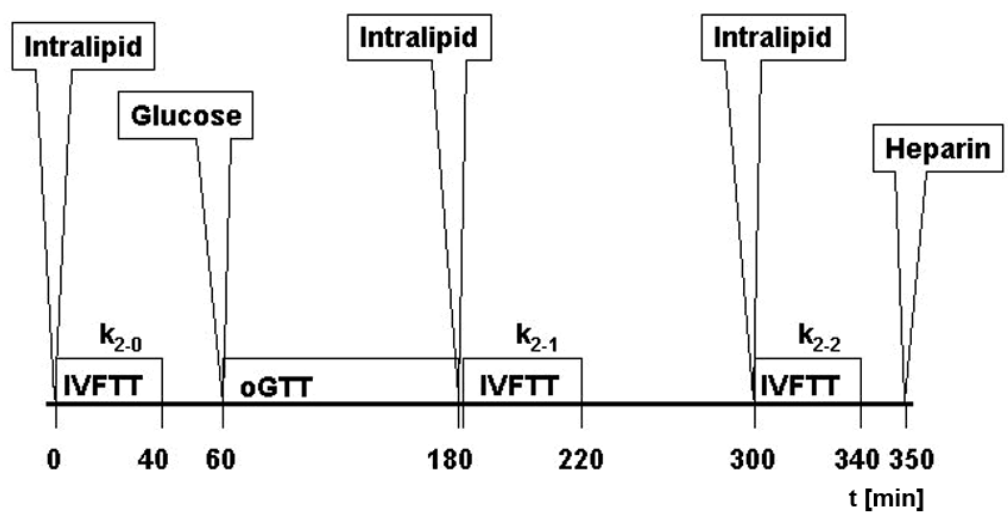

Fig. 1. Design of the experiment

a combination of changes in all the tissues). This can be of considerably great importance for the regulation of postprandial lipemia magnitude due to the fundamental role of insulin in the postprandial phase.

However, the study of changes in LPL activity is limited due to the intricate complexion of LPL. The enzyme is synthesized in parenchymal cells of extrahepatic tissues and transported to capillary endothelium where it binds to heparan sulphate and performs its catalytic function (Goldberg 1996, Olivecrona and Olivecrona 1999). To measure its activity in vitro, enzyme has to be released into the circulation by heparin which displaces the enzyme from the endothelium. However, such a measurement cannot be repeated at short-time intervals and this seriously limits the study of changes in LPL activity. Importantly, the LPL activity response to insulin should be rather fast to accomplish its metabolic role.

To overcome such a limitation, we tested whether the intravenous fat tolerance test (IVFTT) (Lewis et al. 1972, Rössner 1974), that is believed to be a measure of LPL activity in vivo, can be repeated at shorttime intervals to study the acute effects of glucose administration on changes of the total LPL activity in the circulation. In this test, the rate constant of the first order $\left(k_{2}\right)$ for the rate of intravenously administered fat emulsion disappearance is determined. The $\mathrm{k}_{2}$ then reflects the LPL activity in vivo. The IVFTT was performed three times within $6 \mathrm{~h}$ : one hour before as well as 2 and 4 hours after the oral administration of $75 \mathrm{~g}$ of glucose to healthy volunteers.

\section{Methods}

\section{Subjects}

The study group consisted of 11 healthy male volunteers without any known abnormality in lipid metabolism (age: $28.2 \pm 7.3$ years; BMI: $27.1 \pm 2.1 \mathrm{~kg} / \mathrm{m}^{2}$; cholesterol: $\quad 3.84 \pm 0.58 \mathrm{mmol} / \mathrm{l} ; \quad$ HDL-cholesterol: $1.17 \pm 0.23 \mathrm{mmol} / \mathrm{l}$; TG: $1.10 \pm 0.38 \mathrm{mmol} / \mathrm{l}$; glucose: $4.9 \pm 0.5 \mathrm{mmol} / \mathrm{l})$. No medication was regularly taken by the subjects. Normal glucose tolerance was confirmed by the oral glucose tolerance test (oGTT) according to the American Diabetes Association criteria (Genuth et al. 2003) during the screening phase of the study. The study protocol was approved by the Ethical Committee of the Institute for Clinical and Experimental Medicine, Prague, and informed consent was obtained from all the subjects.

\section{Study design}

Briefly, intravenous fat tolerance test (IVFTT) was carried out $1 \mathrm{~h}$ before and 2 and $4 \mathrm{~h}$ after glucose loading during an oGTT (Fig. 1). Glucose (75 g) was dissolved in $300 \mathrm{ml}$ of black tea. In the control experiment, exactly the same design was used, except that black tea without glucose was given to the subjects. The time period between glucose and control experiments without glucose given to the subjects was at least one week. Subjects were examined on an outpatient basis after an overnight fast (12 h) and were instructed to avoid alcohol consumption, tobacco smoking and vigorous exercise the day before the examination. All subjects completed both studies; the order of the studies was randomized.

\section{Intravenous fat tolerance test (IVFTT)}

The test was performed as previously described (Rössner 1974) with slight modifications. First, one indwelling catheter was inserted into the antecubital vein in the right arm for Intralipid ${ }^{\circledR}$ infusion and blood sampling. The baseline blood sample $\left(\begin{array}{ll}0 & \mathrm{~min}\end{array}\right)$ was withdrawn and $20 \%$ Intralipid ${ }^{\circledR}$ (FreseniusKabi AB, Uppsala, Sweden; $0.5 \mathrm{ml} / \mathrm{kg}$ of weight) was then injected within 2 min. Eight blood samples were then withdrawn 
every $5 \mathrm{~min}$ for $40 \mathrm{~min}$.

The blood for nephelometric determination of the $\mathrm{k}_{2}$ rate constant was collected into vacutainers with serum clot activator and separation gel. The vacutainers were then kept at room temperature till centrifugation (10 min, $3000 \times g, 4^{\circ} \mathrm{C}$ ). The separated serum was kept in the same vacutainer till the analysis and then mixed by inverting the tube. Fifty microliters of serum were diluted in $5 \mathrm{ml}$ of saline and the turbidity of diluted serum was measured on MARK IV nephelometer (Scientific Furnishings Ltd, England). The measured values of light scattering index (LSI) were logarithmically transformed and the rate constant $\mathrm{k}_{2}(100 *$ slope of regression line between $\log (\mathrm{LSI})$ and time (min)) was calculated.

Three IVFTTs were performed during each experiment: First one 1 hour before and two others 2 and $4 \mathrm{~h}$ after the subject had received the load of glucose. Consequently, three $\mathrm{k}_{2}$ values were obtained $\left(\mathrm{k}_{2-0}, \mathrm{k}_{2-1}\right.$, $\mathrm{k}_{2-2}$, respectively) (Fig. 1).

\section{Determination of LPL activity}

At the end of the study, 10 minutes after the third IVFTT (time: $350 \mathrm{~min}$ ), heparin (Léčiva, Prague, Czech Republic; $100 \mathrm{IU} / \mathrm{kg}$ ) was i.v. injected to the subjects and $10 \mathrm{~min}$ later blood for in vitro lipoprotein lipase activity assessment was withdrawn. Postheparin plasma was stored at $-80{ }^{\circ} \mathrm{C}$ before determination. LPL activity was determined as described earlier (BengtssonOlivecrona and Olivecrona 1992). Briefly, the samples of postheparin plasma were preincubated with antibody against hepatic lipase (kindly provided by Prof. Hans Jansen, Erasmus University Rotterdam, the Netherlands) and then the activity was measured using Intralipid $\mathbb{R}$ labeled with glycerol- ${ }^{3} \mathrm{H}$-oleate (American Radiolabeled Chemicals, Inc., St Louis, MO, USA) as substrate. To eliminate the interassay variation, all the samples were run in the same assay.

\section{Other methods}

The blood for examination of plasma glucose, immunoreactive insulin, non-esterified fatty acids (NEFA) and TG was taken before and at the end of the first IVFTT (time 0 and $40 \mathrm{~min}$ ), before and 30, 60 and $120 \mathrm{~min}$ after the glucose load (time 60, 90, 120, and 180 min, respectively) as well as before and at the end of the second and the third IVFTT (180, 220, 300, and $340 \mathrm{~min}$, respectively). Plasma glucose concentrations were measured on a Beckman analyzer (Beckman Instruments, Fullerton, CA) using glucose oxidase method, insulin was determined using IRMA kits (Immunotech, Prague, Czech Republic), NEFA and TG concentrations were measured on Roche COBAS MIRA autoanalyzer (Hoffmann-La Roche, Switzerland) using enzymatic kits from Wako, Japan, and Hoffmann-La Roche, Switzerland, respectively.

\section{Statistical analysis}

Data are presented as means \pm S.D. The ANOVA for repeated measures (SYSTAT, SPSS Inc., Chicago, IL, USA) was used to analyze the differences between oGTT and control experiments. Alternatively, paired t-test was used when appropriate.

\section{Results}

The oral glucose administration resulted in the expected increase in glucose and insulin concentrations and suppression of non-esterified fatty acids (NEFA) concentration (Fig. 2). No such changes were observed in control experiments. The course of glycemia after glucose load did not differ from that observed during screening oGTT. Importantly, there were no significant differences in the course of triglyceridemia between both experiments. It can be noted that after each IVFTT, the transient increase in NEFA and TG concentrations was observed. However, the increase in TG concentrations after each IVFTT may reflect an increase not only in serum TG but also in glycerol concentration because Intralipid ${ }^{\circledR}$ contains an approximately equimolar amount of triglycerides and glycerol and the method used for TG determination does not include a correction for glycerol concentration.

The baseline TG concentration in serum was $40 \%$ lower in the oGTT experiment likely due to random day-to-day variation and, accordingly, $\mathrm{k}_{2}$ value $\left(\mathrm{k}_{2-0}\right)$ was $30 \%$ higher (Figs 2 and 3, respectively); these differences were not significant $(p=0.08, p=0.28$, respectively). Importantly, when glucose was given to subjects, the $\mathrm{k}_{2}$ values decreased to $78 \%$ of baseline at $2 \mathrm{~h}$ after glucose administration $\left(\mathrm{k}_{2-1}\right)$ and did not change further after $4 \mathrm{~h}\left(\mathrm{k}_{2-2}\right)$ (Fig. 2). No change of $\mathrm{k}_{2}$ was observed in a control experiment. The difference between $\mathrm{k}_{2}$ changes in both experiments did not reach a statistical significance $(\mathrm{p}=0.06)$. However, when the $\mathrm{k}_{2}$ values were expressed as a percentage of the baseline (to adjust to the difference in the $\mathrm{k}_{2-0}$ values) the difference became significant (Fig. 3). 

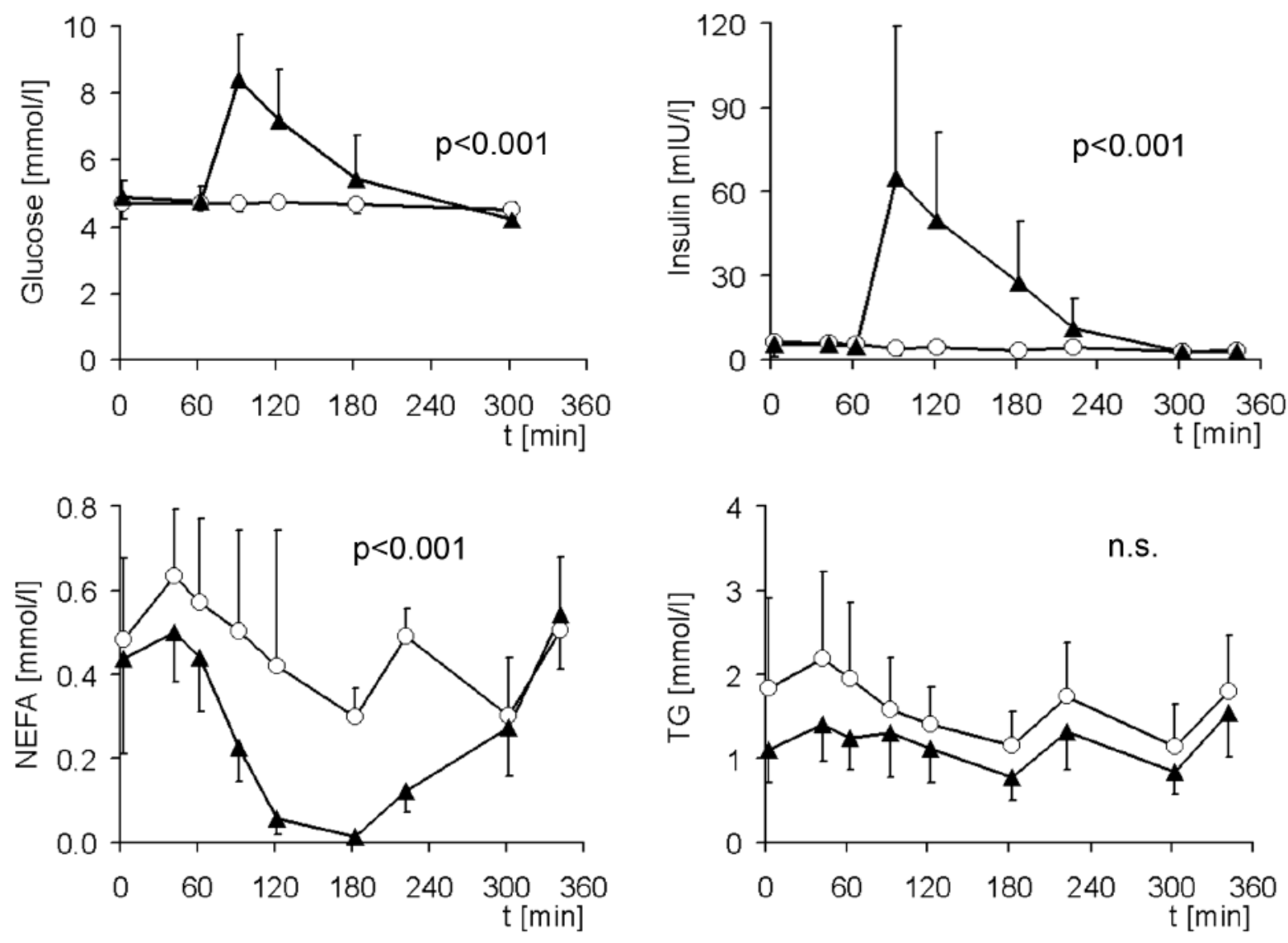

Fig. 2. Changes in glucose, insulin, non-esterified fatty acids (NEFA) and triglyceride concentration during the study. o control experiment, $\Delta$ glucose administration. ANOVA for repeated was used to test differences between control and glucose administration experiments.
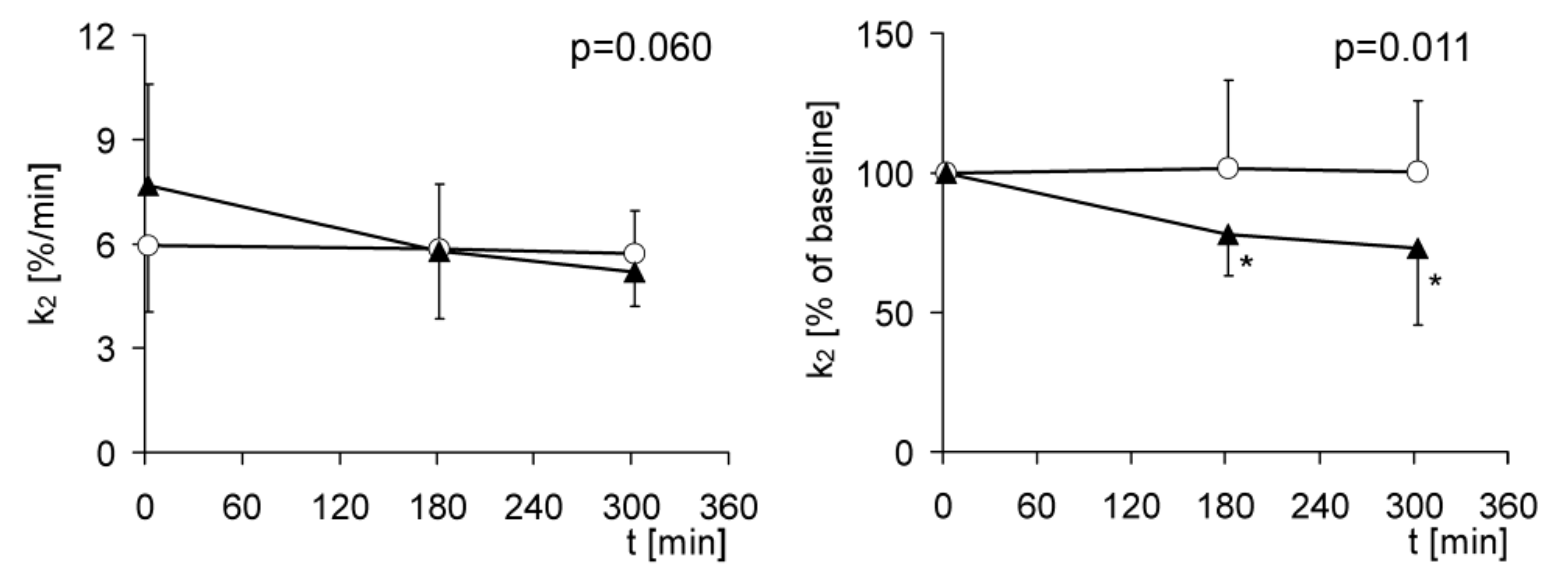

Fig. 3. Changes in $k_{2}$ rate constants and $k_{2}$ rate constants expressed as a percentage of baseline values during the study. $\circ$ control experiment, $\boldsymbol{\Delta}$ glucose administration. * $\mathrm{p}<0.05$ (control versus glucose experiment). ANOVA for repeated measure was used to test differences between control and glucose administration experiments.

In accordance with such findings, the LPL activity measured in vitro in the plasma obtained $10 \mathrm{~min}$ after intravenous heparin application at the end of each experiment was $16 \%$ lower after glucose administration than in the control experiment $(2.88 \pm 0.77 \mathrm{mmol} / \mathrm{l} / \mathrm{h}$ vs. $3.42 \pm 1.02 \mathrm{mmol} / \mathrm{l} / \mathrm{h}, \mathrm{p}<0.05$, paired t-test). 


\section{Discussion}

Using a repeated intravenous fat tolerance test, we demonstrated that an increase in insulinemia and/or glycemia downregulates LPL activity already $2 \mathrm{~h}$ after glucose administration and that such a downregulation persists for at least another $2 \mathrm{~h}$. The decrease in LPL activity was observed even when measured in vitro in postheparin plasma $5 \mathrm{~h}$ after glucose administration.

Such findings are in good agreement with our recent observation that LPL activity measured both in postheparin plasma and as the $\mathrm{k}_{2}$ rate constant is downregulated by hyperinsulinemia and/or hyperglycemia induced in 4-h clamp studies (Kovář et al. 2004). However, the design of the present study allowed us to study the regulation of LPL activity in an experimental setting that is much closer to physiological conditions than that of clamp studies in which hyperglycemia and/or hyperinsulinemia are kept at the adjusted level for several hours.

Contrary to our findings, Cohen and Berger (1990) did not find any significant effect of glucose administration on the $\mathrm{k}_{2}$ rate constant measured in IVFTT. However, they carried out the IVFTTs on different days and it cannot be excluded that intraindividual variations in the $\mathrm{k}_{2}$ rate constant (that may be rather high based on our data (see Fig. 3)), overrode the effect of glucose. In this respect it is worth to mention that $\mathrm{k}_{2}$ rate constant was $10 \%$ lower (though not significantly) $2 \mathrm{~h}$ after glucose administration in Cohen and Berger's experiments.

Lipoprotein lipase is ubiquitously expressed in extrahepatic tissues with adipose tissue and muscle being quantitavely of the primary importance (Olivecrona and Olivecrona 1999). It has repeatedly been demonstrated that insulin downregulates LPL activity in the muscle and upregulates it in the adipose tissue when the LPL activity is measured in tissue samples obtained by biopsy (Lithell et al. 1978, Sadur and Eckel 1982, Yki-Järvinen et al. 1984, Farese et al. 1991). However, until now no data are available on the effect of insulin on the change in total LPL activity in the circulation that is critical with respect to the rate of TRL-triglyceride hydrolysis. It can be assumed that the change in LPL activity in circulation is a sum of opposite changes in different tissues - our results therefore suggest that the insulin effect on LPL activity in the circulation reflects rather its lowering effect in the muscle than its raising effect in the adipose tissue.

In this respect, our findings are in quite good agreement with the observation that 30 -h fasting enhance postheparin LPL activity and that such a change reflects the increased activity in muscles rather than decreased LPL activity in adipose tissue (Ruge et al. 2001, 2005). It was also noted that postheparin LPL activity measured postprandially is lower late in the evening than in the late morning (Arasaradnam et al. 2002) and that may reflect the repeated exposures to periods of hyperinsulinemia and hyperglycemia during the day.

Given that LPL activity decreases after a glucose load, TG concentration would be expected to increase. This is not likely due to a coincidental lowering effect of insulin on NEFA concentration and hepatic VLDL production (Lewis et al. 1993). Furthermore, the LPL activity is unlikely to be a rate limiting factor under conditions of this study.

It is estimated that the capacity of lipoprotein lipase for triglyceride hydrolysis in the circulation is around $40 \mathrm{~g} / \mathrm{h}$ and that should be well above the rate of TG transport in the circulation after a normal meal (Olivecrona and Olivecrona 1999). The fact that triglyceridemia increases postprandially, in spite of such a capacity, is interpreted as a result of local accumulation of fatty acids that release the LPL from the endothelium into the circulation (Saxena et al. 1989, Peterson et al. 1990, Karpe et al. 1992). Our observations provide an alternative explanation that the total LPL activity in the circulation is downregulated postprandially or more precisely that the downregulation of LPL in tissues (such as muscle) is quantitatively more important than the upregulation in other tissues (adipose tissue). The fact that serum NEFA concentrations were even higher in our control experiments, where no change of LPL activity was observed, is in agreement with such an explanation.

We do not have enough data to speculate on the mechanism(s) of such regulations. However, the fact that LPL activity changes occur already $2 \mathrm{~h}$ after glucose administration support the idea that insulin and/or glucose regulate the enzyme activity predominantly at the posttrascriptional level (Ong and Kern 1982, Semenkovich et al. 1989).

Our results suggest that the use of IVFTT repeated at short time intervals is a very promising tool to study the changes of total LPL activity in the circulation. For the first time it allowed us to demonstrate the changes in LPL activity in circulation within $2-3 \mathrm{~h}$ in a given individual. This is impossible when LPL activity is measured in plasma obtained after heparin application due to an extensive release of LPL from tissues and its 
loss from circulation into the liver for degradation (Hultin et al. 1992). It is possible to measure LPL activity repeatedly in samples obtained by biopsy of the skeletal muscles or subcutaneous adipose tissue but such a measurement does not provide information on total LPL activity in the circulation.

Therefore, repeated IVFTT may be a very useful tool for studying the effect of different stimuli (such as hormones, nutrients, drugs, physical activity, etc.) on the acute changes in lipoprotein lipase activity in circulation in vivo. Importantly, results of repeated IVFTT will provide important information on the changes of LPL capacity to hydrolyze triglycerides.

On the other hand, it has to be noted that the repeated IVFTT has a certain limitation. The $\mathrm{k}_{2}$ values obtained using IVFTT correlate inversely with triglyceridemia and this may be partially due to a competition of Intralipid ${ }^{\circledR}$ with endogenous TRL. It can be estimated that the injection of Intralipid ${ }^{\circledR}(0.1 \mathrm{~g}$ of fat $/ \mathrm{kg}$ of weight) should result in an approximately $2 \mathrm{mmol} / \mathrm{l}$ increase of TG concentration and, therefore, the test should not be performed when significant changes of triglyceridemia are expected (such as in postprandial state after a fat load).

In conclusion, using the intravenous fat tolerance test repeated in short-time intervals, we demonstrated that concomitant increase in glycemia and insulinemia results in decrease of LPL activity in circulation of healthy male volunteers already $2 \mathrm{~h}$ after oral glucose administration. The results of our study also indicate that repeated IVFTT is a promising tool for studying acute changes in total LPL activity in circulation.

\section{Acknowledgements}

The work was supported by grant No. NB 7371-3 from the Internal Grant Agency of the Ministry of Health of the Czech Republic. The authors wish to thank Prof. Hans Jansen, Erasmus University Rotterdam, the Netherlands, for his kind gift of antibody against human hepatic lipase, Dr. Petr Stávek, Mrs Dagmar Šišáková and Mrs Dana Körberová for their excellent technical assistance and Dr. Věra Lánská for the statistical analysis of the results.

\section{References}

ARASARADNAM MP, MORGAN L, WRIGHT J, GAMA R: Diurnal variation in lipoprotein lipase activity. Ann Clin Biochem 39: 136-139, 2002.

BENGTSSON-OLIVECRONA G, OLIVECRONA T: Assay of lipoprotein lipase and hepatic lipase. In: Lipoprotein Analysis. A Practical Approach. RE SKINNER, CA CONVERSE (eds), Oxford University Press, Oxford, 1992, pp 169-185.

COHEN JC, BERGER GM: Effects of glucose ingestion on postprandial lipemia and triglyceride clearance in humans. J Lipid Res 31: 597-602, 1990.

ECKEL RH: Lipoprotein lipase. A multifunctional enzyme relevant to common metabolic diseases. $N$ Engl J Med 320: 1060-1068, 1989.

FARESE Jr RV, YOST TJ, ECKEL RH: Tissue-specific regulation of lipoprotein lipase activity by insulin/glucose in normal-weight humans. Metabolism 40: 214-216, 1991.

GENUTH S, ALBERTI KG, BENNETT P, BUSE J, DEFRONZO R, KAHN R, KITZMILLER J, KNOWLER WC, LEBOVITZ H, LERNMARK A, NATHAN D, PALMER J, RIZZA R, SAUDEK C, SHAW J, STEFFES M, STERN M, TUOMILEHTO J, ZIMMET P: Follow-up report on the diagnosis of diabetes mellitus. Diabetes Care 26: 3160-3167, 2003.

GOLDBERG IJ: Lipoprotein lipase and lipolysis: central roles in lipoprotein metabolism and atherogenesis. J Lipid Res 37: 693-707, 1996.

HULTIN M, BENGTSSON-OLIVECRONA G, OLIVECRONA T: Release of lipoprotein lipase to plasma by triacylglycerol emulsions. Comparison to the effect of heparin. Biochim Biophys Acta 1125: 97-103, 1992.

KARPE F, OLIVECRONA T, WALLDIUS G, HAMSTEN A: Lipoprotein lipase in plasma after an oral fat load: relation to free fatty acids. $J$ Lipid Res 33: 975-984, 1992.

KOVÁŘ J, FEJFAROVÁ V, PELIKÁNOVÁ T, POLEDNE R: Hyperglycemia downregulates total lipoprotein lipase activity in humans. Physiol Res 53: 61-68, 2004. 
LEWIS B, BOBERG J, MANCINI M, CARLSON LA: Determination of the intravenous fat tolerance test with Intralipid ${ }^{\circledR}$ by nephelometry. Atherosclerosis 15: 83-86, 1972.

LEWIS GF, UFFELMAN KD, SZETO LW, STEINER G: Effects of acute hyperinsulinemia on VLDL triglyceride and VLDL apoB production in normal weight and obese individuals. Diabetes 42: 833-842, 1993.

LITHELL H, BOBERG J, HELLSING K, LUNDQVIST G, VESSBY B: Lipoprotein-lipase activity in human skeletal muscle and adipose tissue in the fasting and the fed states. Atherosclerosis 30: 89-94, 1978.

MEAD JR, IRVINE SA, RAMJI DP: Lipoprotein lipase: structure, function, regulation, and role in disease. J Mol Med 80: 753-769, 2002.

OLIVECRONA T, OLIVECRONA G: Lipoprotein and hepatic lipase in lipoprotein metabolism. In: Lipoproteins in Health and Disease. DJ BETTERIDGE, DR ILLINGWORTH, J SHEPHERD (eds), Arnold, London, 1999 , pp 223-246.

ONG JM, KERN PA: The role of glucose and glycosylation in the regulation of lipoprotein lipase synthesis and secretion in rat adipocytes. J Biol Chem 264: 3177-3182, 1989.

PETERSON J, BIHAIN BE, BENGTSSON-OLIVECRONA G, DECKELBAUM RJ, CARPENTIER YA, OLIVECRONA T: Fatty acid control of lipoprotein lipase: A link between energy metabolism and lipid transport. Proc Natl Acad Sci USA 87: 909-913, 1990.

RÖSSNER S: Studies on intravenous fat tolerance test. Methodological, experimental, and clinical experiences with Intralipid. Acta Med Scand Suppl 564: 1-24, 1974.

RUGE T, SVENSSON A, ERIKSSON JW, OLIVECRONA T, OLIVECRONA G: Food deprivation increases postheparin lipoprotein lipase activity in humans. Eur J Clin Invest 31: 1040-1047, 2001.

RUGE T, SVENSSON A, ERIKSSON JW, OLIVECRONA T: Tissue-specific regulation of lipoprotein lipase in humans: effects of fasting. Eur J Clin Invest 35: 194-200, 2005.

SADUR CN, ECKEL RH: Insulin stimulation of adipose tissue lipoprotein lipase. Use of the euglycemic clamp technique. J Clin Invest 69: 1119-1125, 1982.

SAXENA, U, WITTE LD, GOLDBERG IJ: Release of endothelial cell lipoprotein lipase by plasma lipoproteins and free fatty acids. $J$ Biol Chem 264: 4349-4355, 1989.

SEMENKOVICH CF, WIMS M, NOE L, ETIENNE J, CHAN L: Insulin regulation of lipoprotein lipase activity in 3T3-L1 adipocytes is mediated at posttranscriptional and posttranslational levels. J Biol Chem 264: 9030-9038, 1989.

YKI-JÄRVINEN H, TASKINEN M-R, KOIVISTO VA, NIKKILÄ EA: Response of adipose tissue lipoprotein lipase activity to acute hyperinsulinaemia in man. Diabetologia 27: 364-369, 1984.

ZECHNER R: The tissue-specific expression of lipoprotein lipase: implications for energy and lipoprotein metabolism. Curr Opin Lipidol 8: 77-88, 1997.

\section{Corresponding author}

J. Kovář, Institute for Clinical and Experimental Medicine, Laboratory for Atherosclerosis Research, Vídeňská 1058/9, 14021 Prague 4, Czech Republic. E-mail: nkov@medicon.cz 